INTERNATIONAL MONETARY FUND

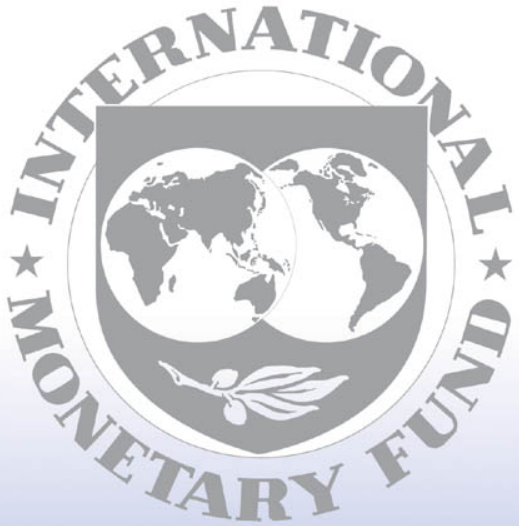

Staff

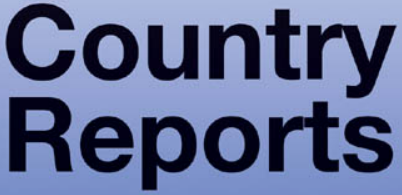




\title{
Benin: Second Poverty Reduction Strategy Paper-Joint Staff Advisory Note
}

The attached Joint Staff Advisory Note (JSAN) of the Second Poverty Reduction Strategy Paper for Benin, prepared jointly by the staffs of the World Bank and the IMF, was distributed with the member countrys Poverty Reduction Strategy Paper to the Executive Boards of the two institutions. The objective of the JSAN is to provide focused, frank, and constructive feedback to the country on progress in implementing its Poverty Reduction Strategy (PRS).

To assist the IMF in evaluating the publication policy, reader comments are invited and may be sent by e-mail to publicationpolicy@imf.org.

\author{
Copies of this report are available to the public from \\ International Monetary Fund • Publication Services \\ 700 19th Street, N.W. • Washington, D.C. 20431 \\ Telephone: (202) 6237430 • Telefax: (202) 6237201 \\ E-mail: publications@imf.org • Internet: http://www.imf.org
}

\section{International Monetary Fund \\ Washington, D.C.}


This page intentionally left blank

CInternational Monetary Fund. Not for Redistribution 


\author{
INTERNATIONAL MONETARY FUND \\ AND \\ INTERNATIONAL DEVELOPMENT ASSOCIATION
}

\title{
BENIN
}

\section{Second Poverty Reduction Strategy Paper Joint Staff Advisory Note}

\author{
Prepared by the Staffs of the International Monetary Fund (IMF) and \\ International Development Association (IDA) \\ Approved by Robert Corker and Anthony Boote (IMF) and \\ Obiageli Ezekwesili (IDA)
}

May 23, 2007

\section{OVERVIEW}

1. Benin's Second Poverty Reduction Strategy Paper, the Straté gie de Croissance pour la Ré duction de la Pauvreté(SCRP), provides a good framework for implementing the Government's growth and poverty reduction agenda over the next three years. It reviews progress under the first PRSP, analyzes constraints to Beninş socio-economic development, and lays out strategic priorities for accelerating growth and reducing poverty over the next three years.

2. The SCRP serves as the basis for a short-term priority action plan for implementing Benin's updated poverty reduction strategy (attached). This plan specifies a number of measures and projects, as well as a set of monitoring indicators, consistent with the strategic orientations of the governments five-year development plan.

3. All levels of society were involved in the development of the strategy. Civil society representatives were included in the thematic groups that drafted the strategy. They were the main participants in open fora held across the country to propose the main axes and revise early drafts of the document. Consultations were also conducted with localities, unions, and members of the private sector.

4. The SCRP provides a new poverty assessment based on analytical work on key socio-economic sectors and on a new household survey (EMICoV). The EMICoV was launched in August 2006, sampling 18,000 households and using both a demographic health survey and a Perceptions of Poverty'que stionnaire. While preliminary, variables representing conditions of life show a modest decline in poverty over the first PRSP period, consistent with a modest increase in per capita income. 
5. The SCRP continues to serve as a good basis for donor coordination and resource mobilization. During preparation of the strategy, the authorities consulted with development partners, and agreed that the SCRP would constitute the sole framework for all donor interventions in Benin. Staffs concur with the authorities that improved coordination and alignment of donor financial and technical assistance would help reduce transaction costs and ensure sound implementation of the poverty reduction strategy. The government and development partners have also started discussions on the implementation of the Paris Declaration in Benin. A stocktaking report on aid effectiveness in Benin was finalized in October 2006 and an agreement has been reached on the M\&E framework of the Paris Declaration. The report calls for improvements in reform monitoring and reporting, and urges greater harmonization of donor interventions.

6. Under the 2002-05 PRSP, economic performance was weaker than envisaged and gains in poverty reduction remained limited. Benin finalized its initial PRSP in December 2002, reached the HIPC Initiative completion point in March 2003, and began receiving assistance under the MDRI in 2006. In the annual PRSP progress reports (APRs) for 2003-06, the government indicated that under the initial PRSP the country made advances in sustaining economic growth in a broadly stable macroeconomic framework, and in improving key social indicators. However, growth performance was much weaker than envisaged, mostly reflecting delays in implementing structural reforms, and overall progress in reducing poverty was slow.

\section{Progress has also been mixed in addressing several issues identified by staff in} earlier JSANs, including (i) inadequate mechanisms for evaluating the impact of policies on the poor; (ii) limited information on the determinants of poverty; and (iv) weak reform implementation capacity. However, the Government has adopted a comprehensive private sector development strategy and started implementing it. Staffs urge the government to use their PRS monitoring indicators more effectively, and stress the need for Benin to strengthen policy implementation and to accelerate progress toward several critical objectives. These include aligning more closely budget execution with PRSP priorities, notably through efforts to increase absorptive capacity and enhance resource management in priority sectors; and accelerate and deepen the structural reform agenda especially in the key cotton, electricity and telecommunications sectors.

\section{THE GROWTH STRATEGY FOR POVERTY REDUCTION}

\section{A. Macroeconomic Scenarios}

8. Staffs agree with the thrust of the macroeconomic policy scenarios and the economic and social objectives set out in the SCRP for 2007-09. The SCRP puts forward a five-pillar development strategy to accelerate growth, reduce poverty, and lift Benin to emerging-economy status. To accelerate growth, the strategy seeks to (i) enhance macroeconomic stability, (ii) promote private sector development, (iii) accelerate 
diversification of the economic and export bases, and (iv) encourage regional integration in the context of WAEMU and ECOWAS. As in the first PRSP, the SCRP targets an average real GDP growth of 7 percent per annum during the three-year period. It presents two alternative scenarios. The first low-growth scenario assumes limited external financial assistance, low public investment, and slow progress toward the MDGs, which limit real GDP growth to an annual average of 4.9 percent. In the second high-growth/MDGs scenario, due to improved absorption capacity and a larger amount of resources dedicated to MDGs, public investment would be higher than under the low-growth scenario by 2 percentage points of GDP, and average output growth would increase to $7 \frac{1}{2}$ percent.

\section{The SCRP's baseline and high-case (MDGs) growth scenarios appear optimistic} in view of delays in implementing reforms under the first PRSP. They are more optimistic than the baseline scenario under the authorities' PRGF-supported program. Public finance management weakened during the two years to end-December 2006 and inflation rose above the 3 percent ceiling of the WAEMU convergence criterion. Moreover, no significant progress has been made in the reform of the energy and telecommunications sectors, while that of the port of Cotonou, handed over to the Millennium Challenge Account (MCA)-Benin, would take longer than initially envisaged. Furthermore, the governments withdrawal from commercial activities in the cotton sector has yet to be completed, and recent experience suggests that the substantial improvement in absorptive capacity and surge in external assistance assumed under the baseline and MDGs scenarios are unlikely to materialize in the next couple of years. For these reasons, staffs are less optimistic about Beninş growth prospects duri ng 200709. In staffs view, output growth would likely be in a $4 \frac{1}{2} 5 \frac{1}{2}$ range during the period. The authorities are therefore encouraged to develop in the first APR an additional low-case scenario that best reflects these more realistic medium-term growth prospects for Benin. The fiscal framework is broadly in line with staff projections.

\section{Challenges remain in safeguarding macroeconomic sustainability and absorbing} scaled-up aid. Long-term fiscal sustainability, a key element of Benins̉ SCRP, remains pivotal to macroeconomic stability. Progress in this area hinges on the authorities' commitment to fiscal consolidation, which includes enhanced domestic revenue collection and continued implementation of prudent expenditure policies, particularly with respect to the wage bill and the deficit of the civil service pension fund. Staffs concur with the authorities that reform of the civil service has to be accelerated and recruitment policies should not jeopardize budget sustainability in the medium term. Going forward, the authorities should be prepared to address potential macroeconomic disturbances from scaledup aid in the post-HIPC/MDRI era. Related macroeconomic policy challenges may be considerable given the size of obtained debt relief and the resources from the US MCA. Debt relief under the enhanced HIPC Initiative and MDRI, in addition to other bilateral debt writeoffs, has reduced Beninss total public debt to below 11 percent of GDP at end-2006, potentially allowing for increased resources for priority sectors. Under the circumstances, in view of the vulnerability of the countrys debt indicators to exogenous shocks, staffs urge the authorities to maintain a prudent borrowing policy, as stressed in the 2006 DSA. 


\section{Accelerated implementation of structural reforms would foster private sector} development, improve competitiveness, and invigorate output growth and employment. Staffs welcome the governmentš strong comm itment to withdraw from commercial activities as part of its determined policy to enhance private sector development. In this context, although a new privately-controlled ginning company will soon take over SONAPRAș cotton factories, privatization of the state-owned telecommunications and electricity companies has been delayed to 2009, allowing time for a review of their technical and financial challenges to be completed. Reform of the Port of Cotonou, now being conducted under the MCA-Benin project, is vital to promote access to markets. Staffs would recommend that the first APR provide a concrete timetable for the implementation of the measures to improve the competitiveness of the Port of Cotonou.

\section{B. Sectoral Policies}

\section{Staffs agree with the SCRP's renewed focus on economic diversification as key} to accelerate growth, but urge the authorities to take necessary actions to make it more operational. In particular, the next Annual Progress Report (APR) should clarify how the Government would address the main bottlenecks to the development and diversification of the agriculture sector, such as high cost and low quality of infrastructure services, lack of technologies and knowledge, and low quality of agricultural products. Staff concur with the SCRP that declining cotton production constitutes a substantial negative risk to the economy and it needs to be addressed. Staffs welcome efforts by the authorities to reorganize the sector in order to boost production, and encourage the authorities to ensure a successful privatization of SONAPRAs̉ cotton ginning factories.

\section{The SCRP rightly emphasizes the importance of infrastructure for growth,} which constitutes one of the main pillars of the strategy. It stresses that key factors for improving the economys competitiveness and grow th potential include reliable and costeffective supply of electricity, improved transport infrastructure, and accessible telecoms services. Staffs emphasize the need to speed up reform of these sectors and to establish and provide the regulatory bodies with needed expert personnel. In the energy sector, although some progress has been made in defining the sector policy and the rehabilitation program for SBEE, the new regulatory code has yet to be approved by Parliament, which delays reaching agreement on the regulators prerogatives. Simila rly, in the telecoms sector, new regulations and enforcement mechanisms are necessary to strengthen the regulatory agency after the recent appointment of its members. In staff's view, the SCRPs' approach to port reform could be expanded, given the sectors critic al economic role. Staff would encourage the authorities to use future APRs to better clarify their objectives and plans in this area. In particular, they should elaborate on how institutional reforms and MCA-supported investment would improve the competitiveness of the Port. 


\section{Human Development}

\section{The SCRP presents preliminary poverty statistics derived from the first round} of the EMICoV launched in August 2006. In the APR issued in 2006, the authorities reported that the incidence of monetary poverty ${ }^{1}$ decreased slightly from 28.5 percent in 2002 to 27 percent in 2005. Based on the first round of the EMICoV, the SCRP reports that monetary poverty has increased to 36.8 percent in 2006 from 28.5 percent in 2002 . However, staffs believe that the poverty estimates for 2006 are not comparable to that of 2002, due to changes in the design and methodology of the surveys. At the same time, EMICoV results based on variables representing conditions of life indicate a modest decline in poverty over the first PRSP period, a development that, in the staffs view, is more consistent with the evolution of per-capita income, results from the perceptions of poverty survey, and those from the EMICoV on changes in income distribution. Staff concur with the authorities that these numbers should be evaluated with caution as they are preliminarily and partial, and encourage the authorities to develop more robust poverty statistics that are comparable over time in the next APR. Staffs also recommend that the National Institute of Statistics strengthen its poverty analysis capacity.

\section{Staffs agree with the SCRP that, at current pace, Benin is unlikely to meet some} MDGs targets. The SCRP notes that the goal of halving extreme poverty and hunger could only be achieved with a sustained implementation of the poverty reduction strategy. It also notes that, while some progress has been made, prospects for meeting targets in the health sector are mixed, and targets with respect to maternal mortality would be missed. However, Benin has made good progress in reducing child mortality and is on track to reach relevant targets in that area. Staffs agree with the SCRP that targets with respect to education could be met for boys, but not for girls, provided that current trends are sustained and ongoing core reforms are enhanced. As for access to potable water for the rural population, the SCRP notes that related targets will be reached, given the recent progress - the relevant ratio improved to 42 percent in 2005 from 35 percent in 2002. It observes that successful pragmatic approaches implemented in partnership with the Bank and other donors allowed Benin to make such achievements. These include strong measures to improve the execution capacity of the sector that more than doubled between 2001 and 2004. Despite such progress in several areas, achieving all targets by 2015 remains a significant challenge; it would require higher economic growth and improved public service delivery. In this light, staffs welcome the Governments̀ renewed emphasis on enhancing economic growth and improving delivery of key basic services.

16. The SCRP shows that overall health indicators have improved slightly over the first PRSP period. New visits to basic health services (37 percent of total population) and the

\footnotetext{
${ }^{1}$ The authorities had estimated the poverty line at CFAF 74,886 (US\$107.44)/year and CFAF 82,224 (US\$157.25)/year for 2002 and 2006, respectively.
} 
proportion of attended deliveries (76 percent) met the relevant PRSP targets in 2005. Progress has also been made in lowering child mortality and controlling HIV/AIDS prevalence. Yet, many constraints need to be addressed in order to meet the MDGs targets in the health sector. In particular, the capacity of the ministry, both at central and decentralized levels, needs to be strengthened in order to improve the performance of the health system. For instance, the number of experienced personnel in health facilities in poor and remote rural areas needs to be increased and the ministry needs to collaborate better with the private sector in planning and supplying health services. Staffs consider that the objectives and priority actions of the strategy described in the SCRP are relevant and consistent with the key challenges identified. Nevertheless, staffs encourage the Government to increase coverage of priority health services, while making it more equitable, and improve access to and quality of services vis-àvis the poor and most vulne rable groups. In particular, construction and renovation of health centers should be expedited and quality of healthcare personnel in rural areas should be improved. Health services of good quality should also be made more affordable to the poor and vulnerable groups. In this light, the Governments recent adoption of a new policy, access to free care for children under five, is an encouraging step.

\section{Significant progress has been made in increasing access to education in general} and particularly to basic education. During 200205, the primary gross enrollment ratio for both genders increased to 94 percent from 90 percent; the gross enrollment ratio for girls increasing by 7 percentage points; and the completion rate increased to 54 percent from 46 percent. The full gratuity in primary education, announced in October 2006, would also contribute to improve access to education. However, the SCRP emphasizes key challenges facing the education sector, in particular persistent geographic and gender disparities, low quality of education despite recent improvements, and the need to further define the measures to address issues in higher education and vocational training.

\section{Staffs agree with the objectives and the strategic pillars of the ten-year education} plan presented in the SCRP. The plan provides a framework for the development of the education sector. Staffs also welcome the new emphasis given to post-primary education and multi-grade schools for sustainable development of the education system. However, staffs encourage the authorities to further prioritize actions and clarify expected outcomes. Staffs also recommend that authorities put in place measures to improve governance and efficiency of the education system; should strengthen management and redeployment of teaching staff; develop multi-grade schools; ensure direct financing and participatory management of community schools; and conduct an institutional audit of ministries in charge of education.

\section{Governance}

\section{The SCRP spells out priorities to improve the business climate and promote} private sector development. It urges that Tax and Customs administration be modernized by fully computerizing their operations, and land tenure be reformed. With a view to strengthening tax compliance and eradicating tax fraud, the government would increasingly 
rely on domestic taxation, expand the tax base, and modernize tax administration. Modernized land tenure is an essential reform for improving the confidence of the private sector and should provide a solid base for property taxation. A modern tax system and tax administration, and better rules for land ownership would lend a critical support to building a business-friendly environment.

\section{The SCRP continues to endorse results-oriented approaches to budget systems} and fiduciary standards. Such approaches aim at improving transparency and efficiency of budget systems and expediting broad-based public administration reforms. Staffs note that the capacity of the budget execution system should be improved so that the government achieves its targets on well-functioning program budgets, and on prompt and rule-based procurement. Capacity for budget management will also have to be improved at the level of sectoral ministries.

21. The SCRP emphasizes the importance of addressing governance, transparency, and corruption. Staff concur with the SCRP that governance problems can negatively affect fiscal revenues, the business climate, productivity, and the countrys ability to mobilize foreign resources. Staffs note, however, that the current court system has unnecessarily delayed audits reports on the central budget, which are vital to budget system transparency, and held back reforms in budget reporting. Staffs encourage the authorities to address this institutional weakness during the first year of the SCRP implementation.

\section{E. Equitable Development}

\section{The SCRP has taken a two-pronged approach to increase allocation of public} resources to disadvantaged areas. First, localities will receive higher financial transfers and local officials better training in order to support local budgets and development plans. Second, investment needs in regional development centers will be addressed in order to provide development-oriented infrastructure. The SCRP further emphasizes that the territorial equity dimension should be taken into account in all steps of budget planning. Staffs concur that budget transfers to local authorities should be increased while the system for intergovernmental transfers is improved, and that local officials should play a key role in monitoring and evaluating implementation of the SCRP. But, safeguards need to be in place to ensure that the fiscal stance remains consistent with macroeconomic stability and low inflation to avoid loss of competitiveness. This should improve the incentive to raise the quality and access to services for the poorest citizens.

\section{CONClusions AND IsSues FOR Discussion by EXecutive Directors}

23. The SCRP notes that progress under the previous PRSP was mixed. It points out that the fiscal position strengthened during the period, while growth slowed to less than half of the targeted goal, and inflation was moderate but higher than in other WAEMU member countries. Staffs support the authorities'commitment to accelerate structural reforms and 
foster private sector development in order to diversify the economic and export bases. Regarding the mixed results on the social front, the SCRP concludes that the new strategy should improve the institutional framework, budget management, and personnel management for basic services. Staff has urged simplification of the SCRPš Priority Action Plan and incorporation of envisaged key actions in the proposed sector program budgets and related Medium-Term Expenditure Framework. This is essential to making the new strategy operational.

\section{Benin's external debt sustainability improved considerably owing to debt relief} under the enhanced HIPC initiative and MDRI. Staffs recommend a rapid adoption of the medium-term strategy to strengthen public finance management so that the fiscal space generated by debt relief and scaled-up external assistance could be used more effectively to increase poverty-reducing and growth-accelerating expenditures.

25. The SCRP sets a good base for monitoring and assessing Benin's performance. It presents a comprehensive framework for reporting the implementation of the strategy. It provides key indicators that allow government, civil society, and development partners to assess progress. It presents an extensive institutional framework for implementation and monitoring which builds on existing institutions and usefully defines a role for local officials in the process. The challenge facing the authorities will be to ensure these institutions function as designed.

26. The SCRP faces certain implementation risks. The most important of these relate to issues noted above, namely, the lack of capacity to steer reforms within the sectors and coordinate reforms across sectors. Staffs note that capacity building is ongoing since the first PRSP and that the new Government is continuing these efforts.

27. The SCRP could be strengthened in future progress reports. It could provide concrete measures to diversify the economy, stress the need to accelerate reforms in utilities and network services, and improve analysis of new poverty data. To facilitate the achievement of key objectives, the authorities should establish appropriate institutions that implement, monitor, and evaluate progress under the strategy.

28. In considering the authorities' PRSP and associated JSAN, Executive Directors' views are sought on whether they agree with the main areas identified by staffs as priorities for strengthening the PRSP and its implementation and the areas identified as key implementation risks. 